\title{
The Effect of Chlorine Concentration on the Optical Constants of SnS Thin Films
}

\author{
Nadir Fadhil Habubi* \\ Sami Salman Chiad* \\ Reem Saadi Khaleel*
}

Received 3, January, 2011

Accepted 20, May, 2011

\begin{abstract}
:
Chlorine doped SnS have been prepared utilizing chemical spray pyrolysis.

The effects of chlorine concentration on the optical constants were studied. It was seen that the transmittance decreased with doping, while reflectance, refractive index, extinction coefficient, real and imaginary parts of dielectric constant were increased as the doping percentage increased. The results show also that the skin depth decrease as the chlorine percentage increased which could be assure that it is transmittance related.
\end{abstract}

Key words: SnS, thin films, optical constants, spray pyrolysis, doping.

\section{Introduction:}

Recently much attention has been payed for $\mathrm{ZnS}$ thin film, since it is a promising material for low cost photovoltaic conversion of solar cell, its conductivity is controllable by using various dopants such as $\mathrm{Al}, \mathrm{Ag}$, and $\mathrm{Cl}$, Tin sulfide exists in variety of phases such as $\mathrm{SnS}, \mathrm{Sn}_{2} \mathrm{~S}_{3}, \mathrm{SnS}_{4}$ and $\mathrm{SnS}_{2}$. Due to bonding characteristics of tin an sulfur, it can have $\mathrm{p}$ or $\mathrm{n}$ type conduction (an excess of tin changes the type of conductivity from $\mathrm{p}$ to $\mathrm{n}$ type). $\mathrm{SnS}$ is reported to have direct band gap and indirect band gap dependent on the conditions of preparation according to PrinceLoferski diagrams, a high conversion efficiency of about $25 \%$ can be obtained using $\mathrm{SnS}$ in photovoltaic devices, in addition it is also useful as heat mirrors in solar control coatings [1-6].

SnS thin films could be prepared using different technique such as chemical deposition, thermal evaporation, chemical bath deposition, Co-evaporation plasma-enhanced, chemical vapor deposition and spray pyrolysis [7-12].

In the present work we show the results of the effect of chlorine doping on the inter-band transition of $\mathrm{SnS}$ and the results of the dispersion parameters deduced from Wimple and Didomenico theory.

\section{Materials and Methods:}

Tin sulphide and chlorine doped tin sulphide were prepared by spray pyrolysis on corning glass substrate kept at a temperature of $400{ }^{\circ} \mathrm{C}$, already were ultrasonically cleand with acetone and methyl alcohol followed by rinsing in distilled water. The deposition parameters such as flow rate, carrier gas pressure and nozzle to substrate distance were kept constant during deposition as $5 \mathrm{ml} / \mathrm{min}$. 1 bar and $29 \mathrm{~cm}$, respectively.

The starting solution was prepared using $\mathrm{SnCl}_{2} .2 \mathrm{H}_{2} \mathrm{O}, \quad \mathrm{n}, \quad \mathrm{n}-$ dimethylethiourea and $\mathrm{NH}_{4} \mathrm{Cl} \cdot \mathrm{SnCl}_{2}$ was dissolved in a mixture of isorpyl alchol and deionized water, while

* Al_Mustansiriyah University, College of Education, Physics Dept 
thiourea and $\mathrm{NH}_{4} \mathrm{Cl}$ were dissolved in deionzed water all of these were milled so that the final concentration would be $0.1 \mathrm{M}$. The chlorine doping was in the range of 1-3\%. Concentration film thickness was estimated by weighing method and were in the range of (300350) nm. Optical absorbance and transmittance measurements for the film were carried out using UV/VIS double beam spectrophotometer (schimadzu $160 \AA 0$ Japan Company) in the wavelength range (300-900) nm

\section{Results and Discussions:}

The optical transmission spectrum at room temperature was taken by using spectrophotometer in the wavelength range of (300-900) nm in order to determine the optical characterization of $\mathrm{SnS}$ and $\mathrm{SnS}: \mathrm{Cl}$ thin films. This spectra is shown in Fig. (1), it is obviously seen that undoped $\mathrm{SnS}$ high transmission about $80 \%$ exhibit, while this value decreases as the chlorine concentration increased all the as deposited films, the transmission curve indicates a smooth increase and nearly saturated at 600 $\mathrm{nm}$, this smooth increase may be due to high crystalline nature of the prepared films [13.14].

The reflectance for all the samples as a function of photon energy is shown in Fig. (2). The curve shows that the reflectance increases as the doping increased up to a certain maxima where all the sample in this maxima nearly have the same value after that these is a fall in the values of reflectivity, this could be attributed to surface roughness.

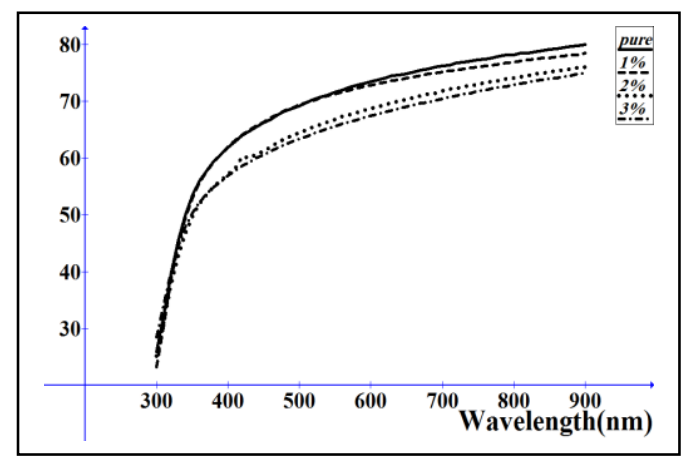

Fig. (1) Transmittance versus wavelength for the as deposited films.

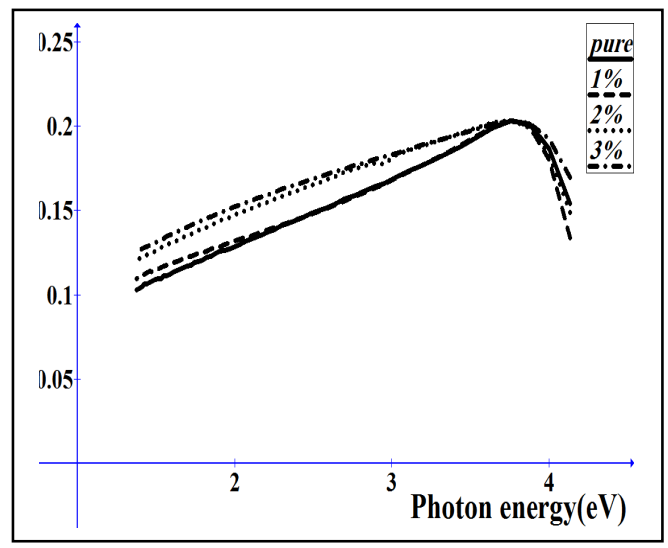

Fig. (2) Reflectance versus photo energy for the as deposited films.

Fig. (3) Shows the refractive index of the $\mathrm{SnS}$ and $\mathrm{SnS}: \mathrm{Cl}$ films as a function of photo energy. the refractive index increase as the doping percentage increased, the behavior of the graphs seems to be the same as the reflectance, the refractive index increase from (1.6-1.93) and it varies with photon energy and percentage and seems to have its maximum value at to the peak maxima which was nearly constant for all the samples. These values of refractive index are within the range found (1.5-4.6) in the literature ${ }^{[15,16]}$.

Fig. (4) Also shows the variation of the imaginary part of the complex refractive index, which is the extinction coefficient $\mathrm{k}$ of the $\mathrm{SnS}$ and chlorine doped $\mathrm{SnS}$ as a function of photon energy. 


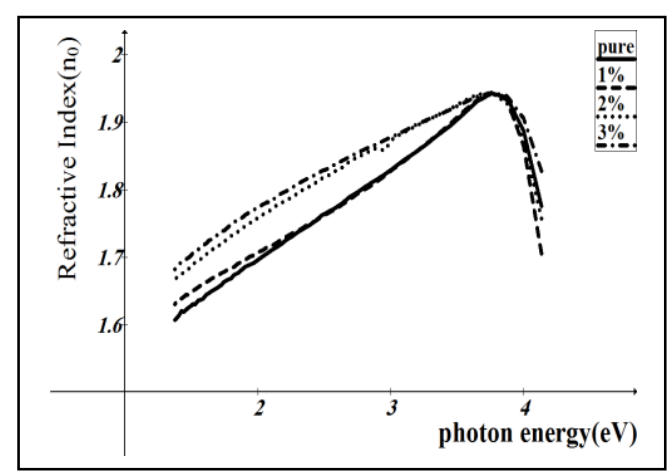

Fig. (3) Refractive index versus photo energy for the as deposited films.



Fig. (4) Extinction coefficient versus photo energy for the as deposited films.

The extinction coefficient (k)of the films was calculated using the relation [13]:

$$
k=\frac{\alpha \lambda}{4 \pi}---(1)
$$

Where $\quad \square \square \square$ is the absorption coefficient, all the values of $\mathrm{k}$ are quite small, which allows the light wave to traverse the sample several times.

As seen in the figure the rapid change in the extinction coefficient at high is due to the band-to-band excitation.

The skin depth could be calculated using the following relation [17]:

$$
\chi=\frac{\lambda}{2 \pi k}
$$

Where $\square$ is the wavelength of the incident photon, $\mathrm{k}$ is the extinction coefficient.
Fig. (5) Shows the variation of skin depth as a function of wavelength for as deposited thin films. It was mentioned that the depth increase as the wavelength increase, this behavior could be seen for the samples, but the skin depth increases as the doping percentage increases so the skin depth is transmittance related.

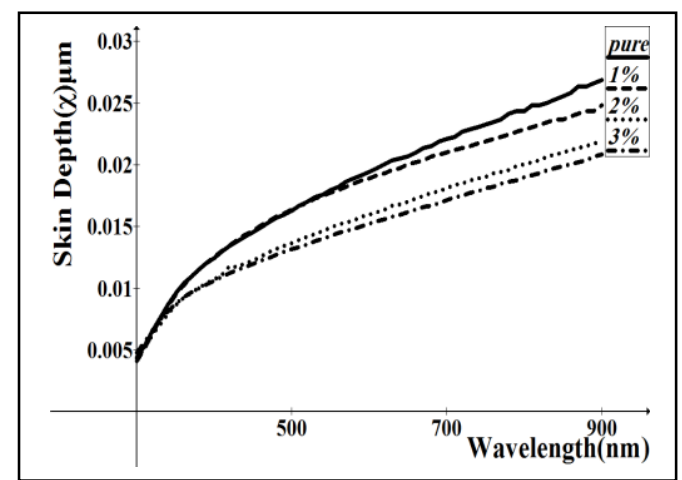

Fig. (5) Skin depth versus wavelength for the as deposited films.

The values of real $\left(\varepsilon_{\mathrm{r}}\right)$ and imaginary $\left(\varepsilon_{\mathrm{i}}\right)$ parts of dielectric constant for different incident photon energies can be obtained from the value of $n$ and $k$ using the relation ${ }^{[16]}$ :

$$
\begin{aligned}
\varepsilon_{\mathrm{r}} & =\mathrm{n}^{2}-\mathrm{k}^{2}---(3) \\
\varepsilon_{i} & =2 n k--(4)
\end{aligned}
$$

In the present study the value of $\left(\varepsilon_{\mathrm{r}}\right)$ increase as the photon energy increase as illustrated by Fig. (6) Showing a maxima above 3.5 and the decrease again for all the samples under investigation, while the values of $\left(\varepsilon_{\mathrm{i}}\right)$ remain almost constant for the photon energy below 3.4, with a sharp decrease after 3.4 .

The behaviors seems to be applied for all the samples under investigation, the value of $\left(\varepsilon_{\mathrm{r}}\right)$ is greater than the value of $\left(\varepsilon_{i}\right)$. 


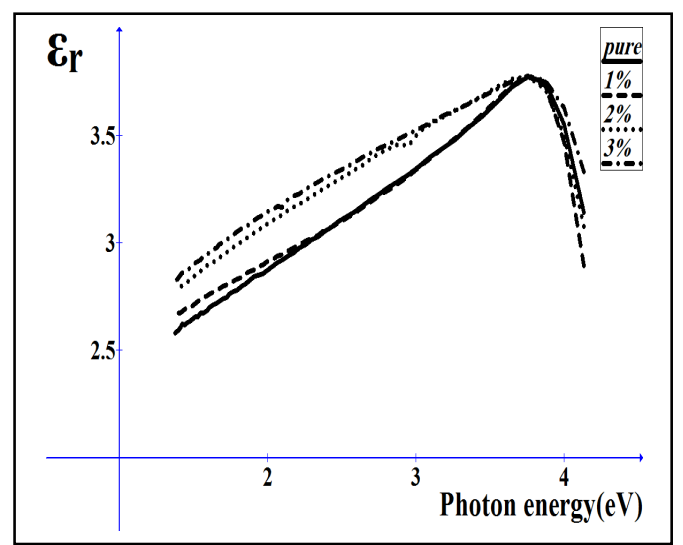

Fig. (6) Real part versus photo energy for the as deposited films.

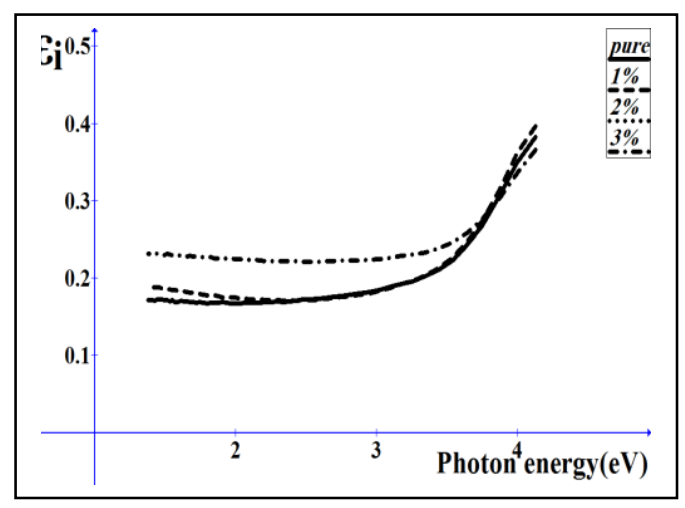

Fig. (7) Imaginary part versus photo energy for the as deposited films.

\section{Conclusions :}

$\mathrm{SnS}$ and chlorine doped $\mathrm{SnS}$ have been successfully prepared by chemical spray pyrolysis the transmittance of undoped $\mathrm{SnS}$ is greater than the doped one, the skin depth show the same behavior which indicate that the skin depth is related to the transmittance, the value of refractive index was in the range of values obtained by other researchers.

The reflectance, refractive index, extinction coefficient, real and imaginary parts of dielectric constant, all of these constant are decrease upon doping.

\section{References :}

1. Devika, M., Reddy, N. K., Ramesh,K., Gumnaselhar, K. R., Gopal, E. S. R. and Reddy, K. T.
R. 2006. Influence of Annealing on Physical Properties of Evaporated SnS Films, Semicond. Sci. Technol., 21:1125-1131.

2. Yue, G. H., Wang, L. S., Wang, X., Chen, Y. Z. and Peng, D. L. 2009. Characterization and Optical Properties of the Single Cryatalline $\mathrm{SnS}$ Nonowire Arrays, Nonoscale Res. Lett., 4: 359-363.

3. Ghosh, B., Das, M., Banerjee, P. and Das. S. 2008. Fabrication of Vacuum Evaporated SnS/CdS Heterojunction for PV Applications, Solar Energy Material and Solar Cells, 39:10091104.

4. Reddy, N. K. and Reddy, K. T. R. 2005. SnS Films for Photo Voltaic Applications:

Physical Investigations on Sprayed $\mathrm{Sn}_{\mathrm{x}} \mathrm{S}_{\mathrm{y}}$ Films, Physica B, 368:25-31.

5. Cifuentes, C., Botero, M., Calderon, C. and Gordillo. 2006. Optical and Structural Studies on SnS Films Grown By CoEvaporation, Braz. J. of Phys., 36(3B):1046-1049.

6. Reddy, K. T. R., Reddy, N. K. and Miles, R. W. 2006. Photovoltaic Properties of SnS Based Solar Cells, Solar Energy Material and Solar Cells, 90: 3041-34046.

7. Avellaneda, D., Delgado, G., Nair, M. T. S. and Nair, P. K. 2007. Structural and Chemical Transformations In SnS Thin Films Used in Chemically Deposited Photo Voltaic Cells, Thin Solid Films, 515: 5771-5776.

8. Ray, S. C., Karanjai, M. K. and Gupta, D. D. 1999. Structure and Photo Conductive Properties of Dip Deposited $\mathrm{SnS}$ and $\mathrm{SnS}_{2}$ Thin Films and Their Conversion to Tin Dioxide by Annealing in Air, Thin Solid Films, 350: 72-78.

9. Li, Y., Tu, J. P., Huang, X. H., Wu, H. M. and Yuan, Y. F. 2007. Net Like SnS/ Carbon Nano Composite 
Films Anode Material for Lithium Ion Batteries, Electro Chemistry Communications, 9: 49-53

10. Ichimura, M., Takeuch, K., Ono, Y. and Aria, E. 2000. Electrochemical Deposition of SnS Thin Films, Thin Solid Films, 361362: 98-101.

11. El-Nahass, M. M., Zeyada, H. M., Aziz, M. S. and El-Ghamaz, N. A. 2002. Optical Properties of Thermally Evaporated SnS Thin films, Optical Materials, 20: 159170.

12. Cheng, S., He, Y. and Chen, G. 2008. Structure and Properties of SnS Films Prepared by ElectroDeposition In Presence of EDTA, Materials Chemistry and Physics, 110: 449453.

13. Turan, E., Kul, M., Aybek, A. S. and Zor, M. 2009. Structure and Properties of SnS Semiconductor
Films Produced by Chemical Bath Deposition, J. Phys. D: Phys., 42:245408 (6pp)

14. Rodriguez, M. C., Martinez, H., Juarez. A. S., Alvarez, J. C., Silver, A. T. and Calixto, N, E. 2009. Structural, Optical and Electrical Properties of Tin Sulfide Thin Films Grown by Spray Pyrolysis, Thin Solid Films, 517: 2497-2499.

15. Nozaki, H., Onoda, M., Sekita. M. and Wada, T. 2005. Variation of Lattice Dimensions in Epitaxial SnS Films on $\mathrm{MgO}$ (001), J. of Sol. Stat. Chem., 178 (1): 245-252.

16. Pankove, J. I. 1971. Optical Processes in Semiconductor Pretice-Hall, New Jersey, 92.

17. Eloy, J. F. 1984. Power Lasers, National School of Physics, Grenoble, France, John Wiley and Sons, 59.

\footnotetext{
تاثير تركيز الكلور على الثوابت البصرية لاغشية كبريتيد القصدير الرقيقة

*نادر فاضل حبويبي *

* سامي سلمان بياد

* الجامعة المستنصرية ـ كلية التربية ـ قسم الفيزياء

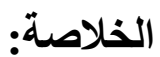

حضر كبريتيد القصدير المشوب بالكلور باستخدام التحلل الكيميائي الحر اري.

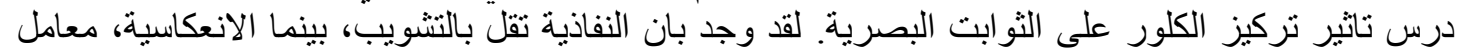





